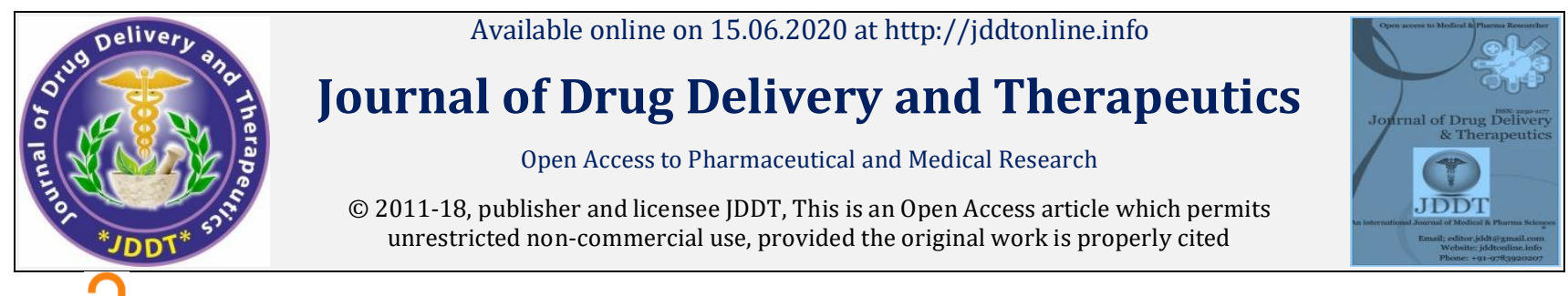

Open Access

Review Article

\title{
Biological Markers as a Novel Approach in Clinical Diagnosis and Management of Diseases
}

\section{Olukayode Olugbenga OROLE ${ }^{1}$, Dooshima Ngulianga NEVKAA ${ }^{2}$, Faith Chidinma TERNA ${ }^{1}$, Alexander

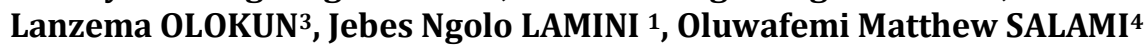

1 Department of Microbiology, Federal University of Lafia, Nigeria

2 Department of Microbiology, University of Agriculture, Makurdi Nigeria

${ }^{3}$ Department of Biological Sciences, Bingham University, Karu, Nasarawa State, Nigeria

${ }^{4}$ Federal School of Medical Laboratory Science, Jos, Plateau State

\begin{abstract}
The adoption and use of biological marker also known as biomarkers in clinical studies and management of disease conditions spans over 40 years. Biological marker are measurable biochemical or molecular alterations that can be adopted as indicator of normal biological or responses to the action of pathogen or pharmacological responses to a therapeutic intervention. Molecules, macro and micro molecules, metabolites, and chemical compounds from the body adopted for use in predicting and monitoring health outcomes are constant from individual to another which qualify them as standard biomarker parameters. Use of biological markers spans clinical screening of an underlying cause of disease, prognosis, predisposition to a disease condition and predicting outcomes of treatment. In the environment, biological markers can be applied to determine the effects of xenobiotic chemicals and reaction effect on living cell. A good marker while being specific, should be easy to measure, cheap, provide correct measurement and outcomes. The objective of this review paper is highlight the different types of biological markers and areas where they are applicable.
\end{abstract}

Article Info: Received 21 March 2020; Review Completed 27May 2020; $\quad$ Accepted 05 June 2020; Available online 15 June 2020

\section{Cite this article as:}

Orole 00, Nevkaa DN, Terna FC, Olokun AL, LAMINI JN, Salami OM, Biological Markers as a Novel Approach in Clinical Diagnosis and Management of Diseases, Journal of Drug Delivery and Therapeutics. 2020; 10(3-s):341-347

http://dx.doi.org/10.22270/jddt.v10i3-s.4105

*Address for Correspondence:

Orole Olukayode Olugbenga, Department of Microbiology, Federal University of Lafia, Nigeria

\section{Introduction}

Biological markers are quantifiable indicators or assessors of biological states or conditions. It is also referred to as biomarkers. The term biological markers have been in existence and use since 1970s, mostly in clinical research on cancer and cardiovascular disease. Biomarker is a measure used to define a pathologic or biologic process and in monitoring progression of a therapy (NIH, 2001). It works by changing progression based on degree of intervention as the disease condition progresses. Biomarkers can measure level of disease through diagnosis or the efficiency of therapy or treatment. An ideal biomarker is non-invasive, and allows measurements to be repeated. It should be simple, quantitative, and accurate in relation to the biological process in question while, progression or such measurement should be predictive and meaningfully aid interpretation of the biological scenario. Example of a nonchemical biomarkers include the size of cysts in polycystic kidney disease, renal pelvic diameter in prenatal ultrasounds and statistics showing $24 \mathrm{~h}$ ambulatory blood pressure recording.

While a risk factor can be independent of a biological process, biomarker is a dynamic viral load and CD4 cell counts to access disease progression of HIV induced immunosuppression and to predict outcomes like opportunistic infections and death, the concentration of blood pressure and serum cholesterol to check for disease progress of vascular injury/atherosclerosis and may serve to predict events leading to cardiovascular and cerebrovascular diseases; the serum levels of C3 and C4 complement to monitor disease processes that involve complement consumption resulting from immune complex activation and may be a prediction for immune-mediated (inflammatory) tissue injury.

Biomarkers accesses factors like rate of heart beat, blood pressure, temperature, pathological processes like disease stage, or pharmacologic responses to a therapeutic intervention (Albert, 2011). Biomarkers are also described 
as measurable substances, structure or process quantifying the relationship between a biological factor and a risk factor. Biomarkers measures biological substances such as macromolecules derived from blood (DNA, RNA, proteins, lipids), body fluids such as urine, stool, sputum or tissues so as to be able to access a person well-being and so be able to plan the best care (Calzone, 2012; IOM, 2010; Allegra et al., 2009). Biological markers' application in medical research and other sciences enables rapid performance of clinical studies, predict disease risks, monitor disease status, and give relevant information that could lead to interventions that can save lives (Albert, 2011).

\section{Nature of Biomarkers}

Biomarkers can be simple or complex in nature. Simple biomarkers include glucose, steroids, lipids, etc. while complex biomarkers include $\mathrm{T}$ cells, auto-antibodies, etc. According to Stimbul and Tavel (2010) biomarkers can be any of the following; a piece of DNA or RNA, any protein, any metabolite, and protein interactions. Sahu et al. (2011) and Hulker (1991) described an ideal biomarker to be characterized as follows;

- It should be specific for a particular disease condition and be able to define different physiological states

- It should give accurate measurement method

- $\quad$ Safe and easy to measure.

- $\quad$ Rapid so as to enable faster diagnosis.

- Cheap and affordable.

- It should be efficient, providing dependable outcomes.

- Consistent between different ethnic groups and genders.

Biomarkers are present in tissue, blood, lymph, and in fluids like breast milk, urine, sputum, and stool, premalignant or malignant cancer cells, and in body secretions and can be analyzed in them (IOM, 2010).

\section{Types of Biomarkers}

\section{A) Biological markers can be classified based on their characteristics as follows \\ i) Imaging biomarkers}

An imaging biomarker is an indicator of the integrity of tissues in the form of an image. It quantifies structural and functional parameters in biological entities. They are nonmolecular in nature and non-biased in obtaining medical images extracted after applying computational models and signal processing to images. An imaging biomarker is both qualitative and quantitative biological parameter, noninvasive, producing results that are intuitive and multidimensional in nature. In lung cancer, simple lesion in the lung to include the size and other characteristics are biomarkers detected by X-ray, CT, or MRI.

\section{ii) Molecular biomarkers}

Molecular biomarkers measures biological samples with biophysical properties. Bodily samples like fluid, tissues or cell components to include nucleic acids can be adopted as molecular markers. These quantify gene mutations or polymorphisms, gene expression, macro and micro molecules.

B) Biomarkers are also classified according to their application as follows:

\section{i) Predisposition Biomarkers}

A predisposition or susceptibility biomarker is an indicator measuring chances of coming down with a disease condition from a medical point of view is yet to have such a medical condition. It is also referred to as risk biomarkers. The biomarkers shows or estimates and determines the risk associated with coming down with or not developing a disease condition, and the risk factor that may increase or decrease the individual risk. Examples of predisposition include genetic biomarker indicating whether one has increased chance of coming down with cancer at a later stage in life, elevated LDL biomarker which indicate increased risk of developing coronary artery disease, and BRCA1/2 mutation which evaluates the likelihood of breast and ovarian cancers. Such biomarkers quantifies the effect lifestyle, nutritional, and other interventions have in predisposing people to disease condition. Biological markers measuring inert response rate to a toxic substance by an organism could be termed as Biomarkers of susceptibility (Strimbu and Tavel, 2010). This involves the genetic predisposition of an individual as it affects susceptibility to chemical materials.

External factors, such as age, diet and health status, can also influence the susceptibility of an individual during exposure to chemicals (IOM, 2010). The biomarker can also be adopted to identifying people who need more monitoring and better management in their therapies (Struewing, 1997). The value of a predisposition biomarker is dependent on available therapy adopted in the management of such clinical cases. Other examples of the predisposition biomarker are Factor $\mathrm{V}$ Leiden (for those predisposed to developing deep vein thrombosis) (Kujovich, 2011), Apolipoprotein E (APOE) gene variations (in people likely to develop Alzheimer's disease) (Genin et al., 2011) and Creactive protein (CRP) level (in individuals with predisposition to coronary disease) (Greenland et al., 2010)

\section{ii) Diagnostic Biomarkers}

Diagnostic biological markers predict without measuring the severity the disease type or subtype a particular individual has (Zauber et al., 2012). The biomarker also identifies individuals at high risk levels for disease as a result of the specificity of their genetic make-up (Calzone, 2012). As a result of the importance of accurate diagnosis of disease, critical determination of a patient condition requiring attention can be better managed using these biomarkers more so that many diseases have subtypes with markedly different reaction to a specific treatment (Best, 2016).

A diagnostic biological marker detects the process leading to a disease condition faster radiography or imaging appliances. Examples of diagnostic biomarker are Sweat chloride used to confirm cystic fibrosis (Farrell et al., 2008), Ejection fraction can be adopted in individuals with heart challenges to identify patients with a subset of disease (those with low ejection fraction or preserved ejection fraction) (Yancy et al., 2013) and gene expression profiling used to segregate patients with diffuse large B-cell lymphoma into subgroups with different tumor cell of origin signatures (Scott et al., 2014).

\section{iii) Prognostic Biomarkers}

A prognostic biomarker accesses the progression of a disease condition and the rate of such progression. It aid in determining the success of medical response by providing relevant data of a patient health outcome (e.g. disease recurrence) irrespective of the treatment and shows if someone is at risk of developing disease (Ruberg and Shen, 
2015). Konstantinos et al. (2018) describes prognostic biomarkers as indicators that suggest the likelihood of occurrence of a clinical condition in an individual not on treatment plan, while others describe them as parameters that help to determine or calculate the probability of disease recurrence or progression.

Oncotype Dx is a prognostic biomarker that determines the likelihood that breast cancer will develop again in an individual that has already been diagnosed and on initial treatment. Examples such as PSA level (prostate cancer prognosis) and PIK3CA mutation status is prognostic in women with HER2-positive metastatic breast cancer undergoing first-line therapy (Baselga et al., 2014).

\section{iv) Predictive Biomarkers}

Predictive biological markers are employed to give information on the likely outcome of a therapy. Prediction biomarkers can highlight among patients, individuals that are likely to respond positively to a choice therapy (Konstantinos et al., 2018). With the help of predictive biomarkers, it is possible to administer a particular therapy to patients with improved chances of treatment success. The difference between prognostic marker and predictive biomarker is prognostic markers measures the total outcome of a disease condition while predictive markers on the other hand on measure the outcome or response to a therapeutic activity. A predictive biomarker only provide information on the effect of a therapy adopted (Oldenhuis et al., 2008), while prognostic biomarker provides information on the likely patient health outcome (e.g. disease recurrence) irrespective of the treatment.

\section{v) Pharmacogenetics biomarkers}

Pharmacogenetics biomarkers help in determining the pharmacological response to a drug or treatment line (Wang et al., 2011). According to Weinshilboum (2003), in many diseases, inherited germ line DNA sequence variants, known as single nucleotide polymorphisms (SNPs), may determine individual differences in drug distribution within the body, metabolism, or effect on target tissues. These markers predict individual's response to the activities of drugs (Wang et al., 2011).

Drug activity biomarkers may be further divided According to Wang et al. (2011) into:-

1. Efficacy biomarkers - indicating the therapeutic effects of a drug

2. Mechanism biomarkers - giving information about the mechanism of action of a drug

3. Toxicity biomarkers - indicating the toxicological effects of a drug

\section{vi) Omics-based biomarkers}

Single analyte biomarkers have been generated and studied over the years because of a preconceived biological association between them and the associated disease (Hammond et al., 2010). An example is adoption of ER as beneficial effect modifier of endocrine therapy (McGuire et al., 1975; Hammond et al., 2010).

\section{vii) Natural history biomarkers}

These are biomarkers that help measure the natural history of a disease and correlate over time with known clinical indicators (Strimbu and Tavel, 2010).

viii) Predisposition biomarkers or surrogate endpoint biomarkers:
A surrogate endpoint is expected to predict clinical benefit or harm or lack of benefit or harm based on epidemiologic, therapeutic, pathophysiologic, or other scientific evidence (Biomarkers Definitions Working Group, 2001; IOM, 2010). They are helpful in identifying the chances or probability of contacting a disease. A surrogate endpoint may provide the clinician either increased certainty that an event is already occurring or is likely occur. For instance, the rising level of a tumor biomarker in the bloodstream of a patient with previously established cancer may be an indication of an impending relapse, and might guide earlier intervention than if the clinician waits for the relapse to be detectable by other means (Biomarkers Definitions Working Group, 2001; IOM, 2010).

\section{ix) Screening Biomarkers and monitoring biomarkers}

Screening Biomarkers and monitoring biomarkers are helpful in screening for people infected by a disease, while Monitoring biomarkers are useful for monitoring previously effected individuals who had been declared disease free, to detect an event earlier than what might be possible with standard clinical approaches (Sahu et al., 2011). Recurrence monitoring biomarkers are beneficial in identifying disease recurrence.

\section{C) Biomarkers can be classified according to its function as follows}

\section{Biomarkers of Exposure}

Biomarkers of exposure quantifies externally released substances or its resulting metabolites or the products formed through reactions between a toxic compound and living cells and measured in a compartment within an organism (WHO, 2001). In this context, chemical concentrations in food, water and air, selected environmental concentrations (e.g., occupational or residential settings) as well as measures of the actual exposures experienced by the individual or population can be measured. Toxicity is produced in specific sites in the body at concentrations and for duration at which the toxic effect become manifest. To this end, labelling a the toxicity of chemical agent in a diseased person requires understanding of the type of effects and the dose at which the effects are produced, understanding the duration and frequency of exposure and level of susceptibility of the concerned individual (WHO, 1991). According to WHO (2001), biomarkers of exposure reveal the distribution of an exogenous compound or its metabolite in the organism.

\section{Biomarkers of Effect}

Hammond et al. (2010) described biomarkers of effect as "measurable biochemical, physiological, behavioral or other alterations within an organism that, depending upon the magnitude, can be recognized as associated with an established or possible health impairment or disease". Examples include the expression of ER and HER2 for therapies in breast cancer, K-ras mutations for antibody therapy, and ALK (anaplastic lymphoma kinase) mutations for therapies in lung cancer (Hammond et al., 2010; Shaw et al., 2010; Allegra et al., 2009; Wolff et al., 2007). Examples of biomarkers of effect include:

\section{a) Hematological biomarkers}

Nielsen et al. (1992) reported that inhibition of the enzymes in the haem synthesis pathway such as ferrochelatase, levulinate and dehydratase has been used as a marker of effect of exposure to lead.

\section{b) Nephrotoxicity biomarkers}


Different types of indicators used as biomarkers of renal damage, have been classified as functional markers (e.g., serum creatinine and 82 macroglobulin), urinary proteins of low or high molecular weight (e.g., albumin, transferrin, retinol- binding globulin, rheumatoid factor, immunoglobulin G), cytotoxicity markers (tubular antigens, e.g., BBSO, BBA, HFS), enzymes (e.g., Nacetylglucosaminidase, agalactosidase) in urine, and biochemical markers (eicosanoids, e.g., 6-keto PGF2a, PGF2, PGF2a and TXB2, fibronectin, kallikrein activity, sialic acid and glycosaminoglycans in urine, and red blood cell negative charges) (WHO,1991).

c) Liver toxicity biomarkers

An important biomarker used to measure the effects of exogenous compounds in the liver is the activities of the enzymes aminotransferases (most often aspartate or alanine aminotransferase) in the serum (Aberle et al., 2011). These enzymes are detected when liver cells have been damaged and have leaked or emptied their contents. Other enzymes that serve as liver toxicity biomarkers include 5-nucleotidase, alcohol dehydrogenase, lactate dehydrogenase, isocitrate dehydrogenase, leucine aminopeptidase, etc. Analysis of specific isoenzymes has been used to overcome this lack of specificity, and serum activities of enzymes such as alkaline phosphatase and 1glutamyl transpeptidase may also be considered as biomarkers of hepatic damage, mostly involving biliary excretion (Aberle et al., 2011).

d) Immunotoxicity biomarkers

Elevated levels of specific antibodies, usually of the Immunoglobulin $\mathrm{E}$ (IgE) type, may indicate existing sensitization. However, not all individuals with elevated levels are symptomatic and not all symptomatic individuals exhibit elevated IgE levels (Wolff, 2007). Patch testing has been used traditionally as a biomarker for identification for allergic skin reactions (Wolff, 2007).

According to Albert (2011), the most sensitive biomarker of an inflammatory response in the bronchoalveolar region is the number of neutrophils in BALF (bronchoalveolar lavage fluid). Increase in protein concentrations in BALF indicate increased permeability of the alveolar or capillary barrier. IOM (2010) stated that Lactate dehydrogenase (LDH) is a cytoplasmic enzyme that is found extracellularly only in the presence of lysed or damaged cells and it's a useful biomarker of pulmonary toxicity. Similarly Shaw et al. (2010) reported that Beta-glucuronidase or similar lysosomal hydrolytic enzymes are excellent markers for the toxicity of inhaled particles.

\section{e) Reproductive and developmental toxicity biomarkers}

Physiological indicators of impaired testicular function or sperm number or characteristics have been identified as biomarkers for the male reproductive system (Strimbu and Tavel, 2010). According to Sahu et al. (2011), these markers include low birth weight, chromosome anomalies, and delayed growth of specific organ systems, mental retardation, and subtle behavioural changes.

\section{f) Neurotoxicity biomarkers}

Owing to the complexities that accompany the functions of the nervous system, neurotoxicity biomarkers could range from effects of chemicals on neural cellular and molecular processes to neurophysiological and neurobehavioural measurements of complex functional entities (Calzone, 2012). According to Hulka (1991), inhibition of plasma and erythrocyte acetylcholine esterase (AchE) can be used as a marker of exposure to organophosphorus compounds and other cholinesterase inhibitors.

\section{Burdens of Disease Biomarkers}

Biomarker in this group shows the level of severity of a disease by comparing disease state disease to a defined accepted standard. While the biomarker accesses the state of the disease. Biomarkers of burden of disease can be accessed depending on what is being monitored. Extract from the synovial fluid can only predict disease level in a single joint, while assessment of blood or urine will show disease status in all joints.

\section{Biomarkers of Efficacy of intervention}

Efficacy of intervention biomarkers ranges from target engagement and pharmacodynamic assays (which assess whether the compound is hitting the desired target and is obtaining the expectant effects and responses to end-result that manifest impact of treatment agent on the disease signs and symptoms (Emrani et al., 2008). These biomarkers are important in drug development as they influence dose selection decisions (Karsdal et al., 2009).

\section{Applications of Biomarkers}

1. Application to chronic kidney disease: kidney disease has historically been described in terms of clinical observations that have been supplemented by the measurements of chemicals in blood or urine which shows differing levels of organ function. There has been a recent increase of interest in the use of biomarkers as tools for clinical research in nephrology.

Examples of classical biomarkers in chronic kidney disease (CKD)

Proteinuria: For many years quantitative proteinuria or albuminuria has been a classical biomarker accounting for renal injury and also serving as a predictor for progress in CKD. The prognostic use of proteinuria shows and predicts later development of nephropathy in type 1 diabetes individuals (Viberti et al., 1982, Mogensen and Christensen 1984). Proteinuria is predictive of nondiabetic CKD progression (Hunsicker et al., 1997, Ruggenenti et al., 1998). Urinary albumin excretion predicts the progress of risk in CKD (Eknoyan et al., 2003). Firstly it is a hybrid marker which may show acute or chronic injury or in many cases a combination of both. Interpreting proteinuria properly needs attention to the clinical context and there may be a requirement of serial determination. An example is about one in three of paediatric type 1 diabetes with microalbuminuria return to normoalbuminuria after 3-6 years of follow up (Rudberg and Dahlquist 1996, Gorman et al., 1999). Other parameters adopted as biomarkers are nephranuria to predict injury in diabetic nephropathy (Patari et al., 2003), urinary exosomes to probe the tubule compartment of the kidney (Zhou et al., 2006).

Cyturia: Urine will continue to be rated above others as a source of biomarker in CKD because its collection is noninvasive and it is readily available and there is also an intimate connection of urine proteins to kidney processes. Hara et al., depicted the presence of podocytes in the sediments of urine of children with a variety of glomerular disease (Hara et al., 1998). More recently it has been shown that podocytes are shed in varying amounts into the urine by both healthy and diseased patients, therefore podocyturia may be quantifiable to urinary creatinine as a ratio, with the ratio differing in active and quiescent disease (Vogelmann et al., 2003). 
The presence of podocytes in urine is an indication of glomerular injury; podocytes are regarded as post-mitotic cells that contribute to glomerular tuft stability (Kriz and Lemley 1999). It is expected that the presence of podocytes in urine correlates with their loss from the glomerulus. Podocytes presence in urine to predict glomerular sclerosis and kidney function loss (Lemeley et al., 2002, Wharram et al., 2005). The excretion rates of nephrin and podocin mRNA have been correlated with loss of renal function subsequently (Szeto et al., 2005).

\section{Biomarkers in nutritional epidemiology}

Research showed that the observed international differences in the occurrence of many chronic diseases such as cancer are mostly due to environmental factors such as diet. Many diet factors contribute to the cause or prevention of disease; these factors range from traditional nutrients, to foods to phytochemicals and contaminants. However the cause of the disease and the diet requires individual risk exposure associations. It is stated by Beaton et al. (1997) that there will always be dietary assessment errors. However the challenge is usually to estimate, understand and make use of the error structure during analysis. To be able to do this effectively has become possible with the presence of biological markers in biological specimen such as blood, urine, and hair which is able to reflect sufficient intake as closely as possible to act as objective indices of true intake. Biomarkers may also be used to account for accuracy of dietary assessment methods. Few biomarkers of dietary intake will be illustrated below

Fatty acids: the fatty acid composition of subcutaneous adipose tissue can be related to estimates of fatty acid intake (Plakke et al., 1983), pentadecanoic acid is a marker for predicting dietary fat within mammalian cells (Wolk et al., 1998). There has also been a considerable association between the total amount of milk product fats produced by a 7 day record and serum cholesterol esters (Smedman et al., 1999).

24 hour urine nitrogen: this is the most popular biological marker, where subject dietary intake is kept constant over elongated periods of time to present a fairly correlated relationship between daily nitrogen intake and daily nitrogen excretion. The use of this method is dependent on assuming that individuals are in nitrogen balance with no accumulation as a result of growth or repair of lost muscle tissue or loss due to injury, slimming or starvation. The obvious accuracy of 24 hour nitrogen as a biological marker has paved way for assuming that it can be used to validate protein intake from various dietary survey methods (Issakson 1980). 24 hour urine has been found to correlate with diet history estimate of protein intake by Van Staveren et al., 1985.

24 hour urine potassium: urine is the main route of excretion of potassium in healthy individuals. Excretion of potassium in the feces constitutes from 5 to $13 \mathrm{mmol}$ per day in Western populations, or $11-15 \%$ of the dietary intake (Bingham et al., 1989). Studies that have obtained at least eight 24-hour urine collections, validated for their completeness, have shown correlations of at least 0.7 between calculated intake and excretion (Bingham et al., 1997). Potassium has an advantage as a biomarker of diet because a greater variety of foods are good sources of potassium than those containing protein, for example vegetables and fruits.

\section{Clinical Applications of glycobiomarkers}

Glycans are characterized uniquely and vary significantly from proteins and nucleic acids in terms of structure, function, and biosynthesis. The development and progression of disease is often times related to variations in glycosylation on tissue proteins and or blood proteins. Glycans released from tissue or blood proteins are known to be an important source of biomarkers. Glycosylation can be adopted as markers for congenital disorders of glycosylation (CDG) (Eklund and Freeze, 2006), ovarian cancers (Leiserowitz et al., 2007), rheumatoid arthritis and systemic lupus erythematosus (Wuhrer, 2007), IgA nephropathy.

\section{Conclusion}

Biomarkers greatly have the advantage of advancing diagnosis and management of disease conditions while it can also be applied to elucidate xenobiotic build up in the environment. Successful management of these conditions is dependent on early detection which a biological marker provides. Biomarkers still have the challenge of similar response to different body fluid or organ sampled. To this end development of a multi-platform approach is recommended while further research studies should be explored.

\section{Conflicts of Interest}

The authors declare no conflict of interest.

\section{References}

1. Aberle DR, Berg CD, "The National Lung Screening Trial: Overview and study design". Radiology, 2011, 258(1): 243253. https://doi.org/10.1148/radiol.10091808

2. Albert MA, "Biomarkers and heart disease". J Clin Sleep Med., 2011, 7(5): 9-11. https://doi.org/10.5664/JCSM.1342

3. Allegra CJ, Jessup JM, Somerfield MR, Hamilton SR, Hammond EH, Hayes DF, et al., "American Society of Clinical Oncology provisional clinical opinion: Testing for KRAS gene mutations in patients with metastatic colorectal carcinoma to predict response to anti-epidermal growth factor receptor monoclonal antibody therapy". Journal of Clinical Oncology, 2009, 27(12): 2091-2096.

https://doi.org/10.1200/JC0.2009.21.9170

4. Baselga J, Cortés J, Im SA, "Biomarker analyses in CLEOPATRA: A phase III, placebo-controlled study of pertuzumab in human epidermal growth factor receptor 2positive, first-line metastatic breast cancer". J Clin Oncol, 2014, 32: 3753-3761. https://doi.org/10.1200/JC0.2013.54.5384

5. Beaton GH, Burema J, Ritenbaugh C, "Errors in the interpretation of dietary assessments". American Journal of Clinical Nutrition, 1997, 65: 1100S-7S.

https://doi.org/10.1093/ajen/65.4.1100S

6. BEST (Biomarkers, EndpointS, and other Tools) Resource. Diagnostic Biomarker. National Center for Biotechnology Information, U.S. National Library of Medicine, 2016. https://www.ncbi.nlm.nih.gov/books/NBK402285/

7. Bingham SA, Gill C, Welch A, Cassidy A, Runswick SA, Oakes S, et al., "Validation of dietary assessment methods in the UK arm of EPIC using weighed records, and 24-hour urinary nitrogen and potassium and serum vitamin $\mathrm{C}$ and carotenoids as biomarkers". International Journal of Epidemiology, 1997, 26(Suppl. 1): S137-51.

https://doi.org/10.1093/ije/26.suppl_1.S137

8. Bingham SA, Goldberg GR, Coward WA, Prentice AM, Cummings JH, "The effect of exercise and improved physical fitness on basal metabolic rate". British Journal of Nutrition, 1989, 61: 155-73. https://doi.org/10.1079/BJN19890106

9. Biomarkers Definitions Working Group, Biomarkers and surrogate endpoints: Preferred definitions and conceptual framework. Clinical Pharmacology and Therapeutics, 2001, 69(3): 89-95. https://doi.org/10.1067/mcp.2001.113989 
10. Calzone KA, "Genetic Biomarkers of Cancer Risk". Seminars in Oncology Nursing, 2012, 28 (2): 122-128. https://doi.org/10.1016/j.soncn.2012.03.007

11. Eklund EA, Freeze $\mathrm{HH}$, "The congenital disorders of glycosylation: a multifaceted group of syndromes". NeuroRx, 2006, 3: 254-263.

https://doi.org/10.1016/j.nurx.2006.01.012

12. Eknoyan G, Hostetter T, Bakris GL, Hebert L, Levey AS, Parving $\mathrm{HH}$, et al., "Proteinuria and other markers of chronic kidney disease: a position statement of the National Kidney Foundation (NKF) and the National Institute of Diabetes and Digestive and Kidney Diseases (NIDDK)". American Journal of Kidney Disease, 2003, 42: 617-622.

https://doi.org/10.1016/S0272-6386(03)00826-6

13. Farrell PM, Rosenstein BJ, White TB, Accurso FJ, Castellani C, Cutting GR, et al., "Cystic Fibrosis Foundation. Guidelines for diagnosis of cystic fibrosis in newborns through older adults: Cystic Fibrosis Foundation consensus report". J Pediatr, 2008, 153(2): S4-S14. https://doi.org/10.1016/j.jpeds.2008.05.005

14. Genin E, Hannequin D, Wallon D, Sleegers K, Hiltunen M, Combarros 0, et al., "APOE and Alzheimer disease: a major gene with semi-dominant inheritance". Mol Psychiatry, 2011, 16(9): 903-907. https://doi.org/10.1038/mp.2011.52

15. Gorman D, Sochett E, Daneman D, "The natural history of microalbuminuria in adolescents with type 1 diabetes". Journal of Pediatrics, 1999, 134: 333-337. https://doi.org/10.1016/S0022-3476(99)70459-2

16. Greenland P, Alpert JS, Beller GA, Benjamin EJ, Budoff MJ, Fayad ZA, et al., ACCF/AHA guideline for assessment of cardiovascular risk in asymptomatic adults: executive summary: a report of the American College of Cardiology Foundation/American Heart Association Task Force on Practice Guidelines. American College of Cardiology Foundation/American Heart Association Task Force on Practice Guidelines Circulation, 2010, 21; 122 (25): 2748-64. https://doi.org/10.1161/CIR.0b013e3182051bab

17. Hammond ME, Hayes DF, Dowsett M, Allred DC, Hagerty KL, Badve S, et al., "American Society of Clinical Oncology/College of American Pathologists guideline recommendations for immunohistochemical testing of estrogen and progesterone receptors in breast cancer". Journal of Clinical Oncology, 2010, 28(16): 2784-2795. https://doi.org/10.1200/JC0.2009.25.6529

18. Hara M, Yanagihara T, Takada T, Itoh M, Matsuno M, Yamamoto T, et al., "Urinary excretion of podocytes reflects disease activity in children with glomerulonephritis". American Journal of Nephrology, 1998, 18: 35-41. https://doi.org/10.1159/000013302

19. Hulka BS, "Epidemiological studies using biological biomarkers: Issues for epidemiologists". Cancer epidemiology, biomarkers and prevention, 1991, 1: 13-19.

20. Hunsicker LG, Adler S, Caggiula A, England BK, Greene T, Kusek JW, et al., "Predictors of the progression of renal disease in the modification of diet in renal disease study". Kidney International, 1997, 51: 1908-1919.

https://doi.org/10.1038/ki.1997.260

21. Institute of Medicine IOM, Implementing Colorectal Cancer Screening: Workshop Summary. Washington, DC: The National Academies Press, 2008.

22. Institute of Medicine IOM, Evaluation of Biomarkers and Surrogate Endpoints in Chronic Disease. Washington, DC: The National Academies Press, 2010.

23. Isaksson B, "Urinary nitrogen output as a validity test in dietary surveys". American Journal of Clinical Nutrition, 1980, 33: 4-5. https://doi.org/10.1093/ajcn/33.1.4

24. Karsdal MA, Henriksen K, Leeming DJ, Mitchell P, Duffin K, Barascuk N, et al., "Biochemical markers and the FDA Critical Path: how biomarkers may contribute to the understanding of pathophysiology and provide unique and necessary tools for drug development". Biomarkers, 2009, 14: 181e202. https://doi.org/10.1080/13547500902777608

25. Konstantinos S, Konstantinos P, Metcalfe PD, Svensson D, Weatherall J, Brown G, "Distinguishing prognostic and predictive biomarkers: an information theoretic approach". Bioinformatics, 2018, 34(19): 3365-3376. https://doi.org/10.1093/bioinformatics/bty357

26. Kriz W, Lemley KV, "The role of the podocyte in glomerulosclerosis". Current Opinions in Nephrology
Hypertension, 1999, 8: 489-497.

https://doi.org/10.1097/00041552-199907000-00014

27. Kujovich JL, "Factor V. Leiden thrombophilia". Genetic Medical, 2011, 13 (1):1-16.

https://doi.org/10.1097/GIM.0b013e3181faa0f2

28. Leiserowitz GS, Lebrilla C, Miyamoto S, et al., "Glycomics analysis of serum: a potential new biomarker for ovarian cancer?" International Journal of Gynecological Cancer, 2007, 18: 470-475. https://doi.org/10.1111/j.15251438.2007.01028.x

29. Lemley KV, Lafayette RA, Safai M, Derby G, Blouch K, Squarer A, et al., "Podocytopenia and disease severity in IgA nephropathy". Kidney International, 2002, 61:1475-1485. https://doi.org/10.1046/j.1523-1755.2002.00269.x

30. McGuire WL, Chamness GC, Costlow ME, Richert NJ, "Steroids and human breast cancer". Journal of Steroid Biochemistry, 1975, 6(5): 723-727. https://doi.org/10.1016/00224731(75)90059-X

31. Mogensen CE, Christensen CK, "Predicting diabetic nephropathy in insulin-dependent patients". The New England Journal of Medicine, 1984, 311: 89-93. https://doi.org/10.1056/NEJM198407123110204

32. Nielsen J, Welinder H, Horstmann V, Skerfving S, "Allergy to methyltetrahydrophthalic anhydride in epoxy resin workers". Br J Ind Med, 1992, 49: 769-775. https://doi.org/10.1136/oem.49.11.769

33. NIH Biomarkers Definitions Working Group, "Biomarkers and surrogate endpoints: Preferred definitions and conceptual framework". Clinical Pharmacology Therapy, 2001, 69: 89-95. https://doi.org/10.1067/mcp.2001.113989

34. Oldenhuis CN, Oosting SF, Gietema JA, de Vries EG, "Prognostic versus predictive value of biomarkers in oncology". Eur J Cancer, 2008, 44(7): 946-953. https://doi.org/10.1016/j.ejca.2008.03.006

35. Patari A, Forsblom C, Havana M, Taipale H, Groop PH, Holthofer $\mathrm{H}$, "Nephrinuria in diabetic nephropathy of type 1 diabetes". Diabetes, 2003, 52: 2969-2974. https://doi.org/10.2337/diabetes.52.12.2969

36. Plakke T, Berkel J, Beynen AC, Hermus RJJ, Katan MB, "Relationship between the fatty acid composition of the diet and that of the subcutaneous adipose tissue in individual human subjects". Human Nutrition Applied Nutrition, 1983, 37: 365-372

37. Ruberg SJ, Shen L, "Personalized medicine: four perspectives of tailored medicine". Stat. Biopharm. Res., 2015, 7: 214-229. https://doi.org/10.1080/19466315.2015.1059354

38. Rudberg S, Dahlquist G, "Determinants of progression of microalbuminuria in adolescents with IDDM". Diabetes Care, 1996, 19:369-371. https://doi.org/10.2337/diacare.19.4.369

39. Ruggenenti P, Perna A, Mosconi L, Pisoni R, Remuzzi G, "Urinary protein excretion rate is the best independent predictor of ESRF in non-diabetic proteinuric chronic nephropathies". Kidney International, 1998, 53: 1209-1216 https://doi.org/10.1046/j.1523-1755.1998.00874.x

40. Sahu P, Pinkalwar N, Dubey RD, Paroha S, Chatterjee S, Chatterjee T, "Biomarkers: An Emerging Tool for Diagnosis of a Disease and Drug Development". Asian J Res Pharm Sci., 2011, 1: 9-16.

41. Scott DW, Wright GW, Williams PM, Lih CJ, Walsh W, Jaffe ES, et al., "Determining cell-of-origin subtypes of diffuse large Bcell lymphoma using gene expression in formalin-fixed paraffin-embedded tissue". Blood, 2014; 123(8):1214-7. https://doi.org/10.1182/blood-2013-11-536433

42. Shaw AT, Yeap BY, Solomon BJ, Riely GJ, Gainor J, Engelman JA, et al., "Effect of crizotinib on overall survival in patients with advanced non-small-cell lung cancer harbouring ALK gene rearrangement: A retrospective analysis". Lancet Oncology, 2010, 12(11):1004-1012. https://doi.org/10.1016/S1470-2045(11)70232-7

43. Smedman AEM, Gustafsson IB, Berglund LGTM, Vessby BOH, "Pentadecanoic acid in serum as a marker for intake of milk fat: relations between intake of milk fat and metabolic risk factors". American Journal of Clinical Nutrition, 1999, 69: 2229. https://doi.org/10.1093/ajcn/69.1.22

44. Strimbu K, Tavel JA, "What are Biomarkers? Current Opinion in HIV AIDS", 2010, 5(6): 463-466. https://doi.org/10.1097/COH.0b013e32833ed177 
45. Struewing JP, Hartge P, Wacholder S, Baker SM, Berlin M, McAdams M, et al., "The risk of cancer associated with specific mutations of BRCA1 and BRCA2 among Ashkenazi Jews". N Engl J Med., 1997, 15; 336(20):1401-1408. https://doi.org/10.1056/NEJM199705153362001

46. Szeto C, Lai KB, Chow KM, Szeto CY, Yip TW, Woo KS, et al., "Messenger RNA expression of glomerular podocyte markers in the urinary sediment of acquired proteinuric diseases". Clin Chim Acta, 2005, 361: 182-190.

https://doi.org/10.1016/j.cccn.2005.05.016

47. Van Staveren WA, de Boer JO, Burema J, "Validity and reproducibility of a dietary history method estimating the usual food intake during one month". American Journal of Clinical Nutrition, 1985, 42: 554-559.

https://doi.org/10.1093/ajcn/42.3.554

48. Viberti GC, Hill RD, Jarrett RJ, Argyropoulos A, Mahmud U, Keen $\mathrm{H}$, "Microalbuminuria as a predictor of clinical nephropathy in insulin-dependent diabetes mellitus". Lancet, 1982, 1:1430-1432. https://doi.org/10.1016/S01406736(82) 92450-3

49. Vogelmann SU, Nelson WJ, Myers BD, Lemley KV, "Urinary excretion of viable podocytes in health and renal disease". American Journal of Physiology, 2003, 285:F40-F48. https://doi.org/10.1152/ajprenal.00404.2002

50. Wang L, McLeod HL, Weinshilboum RM, "Genomics and drug response". New England Journal of Medicine, 2011, 364(12): 1144-1153. https://doi.org/10.1056/NEJMra1010600

51. Weinshilboum R, "Inheritance and drug response". New England Journal of Medicine, 2003, 348(6): 529-537. https: //doi.org/10.1056/NEJMra020021

52. Wharram BL, Goyal M, Wiggins JE, Sanden SK, Hussain S, Filipiak WE, et al., "Podocyte depletion causes glomerulosclerosis: diphtheria toxin-induced podocyte depletion in rats expressing human diphtheria toxin receptor transgene". Journal of American Society of Nephrology, 2005, 16: 2941-2952. https://doi.org/10.1681/ASN.2005010055
53. WHO. IPCS Environmental Health Criteria 119: Principles and methods for the assessment of nephrotoxicity associated with exposure to chemicals. Geneva: World Health Organization, 1991, $266 \mathrm{pp}$

54. WHO. IPCS Biomarkers in Risk Assessment: Validity and Validation. 2001.

http://www.inchem.org/documents/ehc/ehc/ehc222.htm. Accessed on: 3/04/2020

55. Wolff AC, Hammond ME, Schwartz JN, Hagerty KL, Allred DC, Cote MD, et al., "American Society of Clinical Oncology/College of American Pathologists guideline recommendations for human epidermal growth factor receptor 2 testing in breast cancer". Journal of Clinical Oncology, 2007, 25(1): 118-145. https://doi.org/10.1200/JC0.2006.09.2775

56. Wolk A, Vessby B, Ljung H, Barrefors P, "Evaluation of a biological marker of dairy fat intake". American Journal of Clinical Nutrition, 1998, 68: 291-295. https://doi.org/10.1093/ajcn/68.2.291

57. Wuhrer M, "Glycosylation profiling in clinical proteomics: heading for glycan biomarkers". Expert Reviews in Proteomics, 2007, 4: 135-136. https://doi.org/10.1586/14789450.4.2.135

58. Yancy CW, Jessup M, Bozkurt B, Butler J, Casey DE Jr, Drazner $\mathrm{MH}$, et al., "ACCF/AHA guideline for the management of heart failure: a report of the American College of Cardiology Foundation/American Heart Association Task Force on practice guidelines". Circulation, 2013, 15; 128:e240-327.

59. Zauber AG, Winawer SJ, O'Brien MJ, Lansdorp-Vogelaar I, van Ballegooijen M, Hankey BF, et al., "Colonoscopic polypectomy and long-term prevention of colorectal-cancer deaths". New England Journal of Medicine, 2012, 366(8): 687-696. https://doi.org/10.1056/NEJMoa1100370

60. Zhou H, Yuen PST, Pisitkun T, Gonzales PA, Yasuda H, Dear JW, et al., "Collection, storage, preservation, and normalization of human urinary exosomes for biomarker discovery". Kidney International, 2006, 69: 1471-1476. https://doi.org/10.1038/sj.ki.5000273 